\title{
Energy balance in childhood and adolescence
}

\section{By J. V. G. A. Durnin, Institute of Physiology, University of Glasgow, Glasgow G12}

A little over 2 years ago the Nutrition Society held a symposium on the 'Regulation of Energy Balance'. Many of the papers were of interest, but not of much relevance to the understanding of energy balance in normal individuals, particularly in children.

Before dealing with the proper subject matter of this presentation, it might be useful to consider some of the points raised by one of the papers of the previous symposium (Miller, I 982 ) since it stimulates some re-analysis in relation to terminology, terms such as 'gross energy', 'net energy', 'cold'- and 'dietary-induced' thermogenesis, etc. These points are of importance not only to remove confusion about the correct understanding of the terms, but also to dispel muddle in the minds of some nutritionists resulting from an illogical interpretation of some simple physiological phenomena.

\section{Energy balance and the 'net' cost of 'thermogenesis'}

Most of the misunderstanding centres on energy expenditure. Energy balance, as is well known and often repeated in circumstances like this, reflects the balance between energy intake and energy expenditure taking into consideration the particular physiological circumstances of the situation. For example, in pregnancy, it appears to me self-evident, as a physiologist, that energy balance is not simply the balance between the energy available to the body from the food eaten and the energy expended in all the various normal processes of daily life, but that this must also make provision for an adequate extra quantity of energy to cover the requirements for normal growth of the fetal and maternal tissues. Similarly, in lactation, extra energy is needed for the production of breast-milk. During the period of the life-span, when growth is a normal phenomenon from infancy to the stage of complete physical maturation, a component for growth has to be available over and above the energy expended. In all these physiological states, energy balance will require an appropriate excess of energy intake over expenditure.

The energy taken into the body in the food is not all available for metabolic processes; some of it is lost to the body, principally in the urine and faeces. Therefore, only the net energy from food ought to be considered. The total quantity of energy expended, however it is measured (whether by heat production or by the oxygen consumed by the body), is the amount against which to set the net energy intake, if an attempt is being made to assess whether or not a physiological balance exists. This energy expenditure will include, at various times, only the basal metabolic rate (BMR) (as during part of the sleeping period), plus specific 
dynamic action (as after a meal) and perhaps an 'activity' component (as during physical exercise either at work or otherwise).

It is quite erroneous to pretend that we can measure, in any exact physiological sense, the various forms of so-called 'thermogenesis', and the attempt to quantify these by obtaining a net value for exercise, or the effects of a meal, or the effects of cold, or any other influences, by simply deducting an amount to cover the BMR, is extraordinarily naive. For those unfamiliar with this concept, it consists of subtracting the value of the BMR (say $4 \mathrm{~kJ} / \mathrm{min}$ ) from the gross energy expenditure in physical activity (say $17 \mathrm{~kJ} / \mathrm{min}$ ) or after a meal (say $5 \mathrm{~kJ} / \mathrm{min}$ ) and suggesting that the resultant value $(13 \mathrm{~kJ} / \mathrm{min}$ for the activity and $\mathrm{I} \mathrm{kJ} / \mathrm{min}$ for the dietary 'thermogenesis') is the net effect of the exercise or of the food.

The pointlessness and the error of this manoeuvre is the assumption that the BMR is a constant, independent of whatever else is occurring in the body. An elementary knowledge of physiology should prevent such a conclusion. The BMR is the sum of all the metabolic activity of the body during a specified rest situation. That is, it is made up of the energy required, or the $\mathrm{O}_{2}$ consumed, by the brain, the heart, the skeletal muscles, the kidneys, the lungs, the liver and gut, the skin, and all the other tissues and organs of the body in that resting state. During physical activity, during exposure to cold, and during digestion and absorption, there is a redistribution of blood in the body. The brain is relatively immune from this, but other organs are not; e.g. the liver and the gut, the skin, the kidneys, the skeletal muscles, and other regions of the body have a blood flow and energy utilization which are subject to very considerable fluctuations, dependent on the particular needs of the body at the time. BMR is therefore not a constant, and making a deduction for it on the assumption that it is, is quite illogical. It also seems mostly unnecessary. In fact, the real net effect of exercise, or cold, or diet, may often be larger than nutritionists have suggested, but it cannot be accurately estimated.

The point can surely be made, if it is thought critical to the argument, that any particular exercise, or the intake of a given amount of food energy, has resulted in an increase in the metabolic rate of the body of 20 or $200 \%$ of the basal level or whatever the case may be, without trying to be spuriously exact about the net increase, nor with labelling these effects with emotive names (in which I include the word 'thermogenesis').

\section{Definition of 'thermogenesis'}

'Thermogenesis', when considered dispassionately, is really not a very satisfactory term for the physiological process it purports to describe. The word itself means 'the generation of heat'. But this is a secondary phenomenon, often not even particularly useful to the body since it must be removed if the body temperature is to remain stable. What is happening when the body takes in food, or when physical activity occurs, is that there is an increased activity of the gut, the liver, skeletal muscles, or other organs and tissues, which require extra $\mathrm{O}_{2}$ and result in increased energy expenditure. The 'thermogenesis' results from the increased energy expenditure. 'Dietary (or exercise)-induced thermogenesis' could 
be more accurately, and almost as briefly, described as the 'extra energy cost of eating' or 'of exercise'.

\section{Some practical advantages of the use of $B M R$}

These are not arguments against the use of the BMR as a reference in many situations. It is quite illustrative, in my own experience, to evaluate some influence as having had an effect, for example, equivalent to a certain ratio of the BMR. Indeed the last WHO/FAO/UNO Expert Consultation on Energy and Protein Requirements, which met in Rome in the autumn of $198 \mathrm{I}$ (the report is still unpublished), adopted a suggestion of mine that energy requirements might be based on calculations of the energy expended in work, or in leisure, as represented by the BMR multiplied by an appropriate factor. For instance, the energy expended during the working period by an office worker might average out at perhaps $I \cdot 7$ times the BMR; a physically strenuous occupation might involve, on average, the expenditure of three times the BMR. Very active sporting recreational activities, of short duration, might have an energy expenditure of five or ten times or more the BMR.

There does not seem to me to be any biological illogicality to this sort of concept, and it provides a useful procedure for comparing differing situations independently of variations in individuals or in population groups.

It has an advantage over using gross values of energy (e.g. $7 \mathrm{~kJ} / \mathrm{min}$ or approximately $3.4 \mathrm{MJ} / 8 \mathrm{~h}$ for an average energy expenditure at a sedentary occupation) since no complexity need arise because of differing body sizes. There is equally no need to express energy as units per kg body-weight.

It is perhaps tangential to the main purpose of this paper to have been discussing 'net' and 'gross' energy, but clarification of areas where confusion seems to arise may help towards a better understanding of energy balance in general.

\section{'Growth' and its importance in energy balance}

It was suggested in the early part of this presentation that energy balance in childhood and adolescence should include enough extra energy, over and above the expenditure, to allow for normal growth. We are in an area of real difficulty here. Firstly, what is normal growth? Secondly, how do we rationalize the apparently very small amounts of energy needed for growth with the inhibited growth patterns seen in populations who must be no more than marginally nourished? For example, the energy needed for growth (World Health Organization, 1973) is shown in Table I to be of apparently almost insignificant quantities.

It is difficult to reconcile these very small, partly theoretical values with real-life situation. For example, in growth-retarded children it is seldom that growth is non-existent. Therefore, some energy must be available for growth. The deficit apparently preventing normal growth may thus be no more than $40-80 \mathrm{~kJ}$ ( $10-20$ $\mathrm{kcal}) / \mathrm{d}$. How is it possible that this very small amount of energy does not more often seem to be compensated for in some non-nutritional way: slight economies in 
Table I. Energy for growth related to total daily energy intake (World Health Organization, 1973)

\begin{tabular}{|c|c|c|c|c|}
\hline \multirow[b]{2}{*}{ Age (years) } & \multicolumn{2}{|c|}{ Energy for growth } & \multicolumn{2}{|c|}{ Total daily intake } \\
\hline & $\mathrm{MJ} / \mathrm{d}$ & $\mathrm{kcal} / \mathrm{d}$ & MJ & kcal \\
\hline $2-3$ & 0.13 & 30 & $4 \cdot 2$ & 1000 \\
\hline 5 & 0.15 & 35 & $6 \cdot 3$ & 1500 \\
\hline 10 & 0.13 & 30 & 8.4 & 2000 \\
\hline $13-15$ & 0.21 & 50 & $8 \cdot 4-10 \cdot 5$ & $2000-25$ \\
\hline
\end{tabular}

movement perhaps, a few extra minutes a day of inactivity? Is it correct that the quantities of energy needed for growth are really so low? These are difficult questions to answer scientifically, although I suspect many parents, witnessing the ravenous appetites of their growing children, would have no doubts about the clear inaccuracy of the information.

Certainly, if these values are anything near to being accurate, they are quite incapable of being measured by our available techniques. It is impossible to measure food intake and energy expenditure with sufficient precision to detect whether or not adequate energy is available for growth. The indirect approach, of measuring energy intake in the food and of following longitudinally the rate of growth, is the only way of assessing the level at which energy balance is being attained in children or adolescents. Of course, the fact that satisfactory energy balance exists (without measuring the level of this energy balance), can be determined from longitudinal data on growth alone. Such longitudinal studies on children incorporating energy intakes are so rare as to be virtually non-existent in Britain, although there are honourable exceptions in the USA, notably those by Beal (1980), in whose book other US studies are also described.

\section{'Normal growth'}

To return to the first imponderable, 'what is normal growth?' Here we are in a region of only part science and, to a large extent, part emotion and prejudice. The most important area of non-scientific assessment is in the concept of 'growth potential' as if this were automatically synonymous with maximum growth and with the physiological ideal. I know of very little biological evidence to support this thesis for man. Man is not only a physical animal where size may be directly related to well-being and survival. Man has a brain and his best adaptation to his environment might not always necessitate maximum growth. Quite apart from the possibility that there may be disadvantages for health in the attainment of maximum growth (and there is at least the chance that certain degenerative conditions are more common in big people) the biological possibility could certainly exist that growth might be overstimulated by appropriate stimuli. I have always failed to understand why it is automatically assumed that a population of big people is superior, in the physiological sense, to one of somewhat smaller people. Even from the simple physical standpoint, there is much contradictory 
evidence. Physical activities, either in working situations or in sport or leisure, often do not have a high correlation between body size and function, other than when simple strength is concerned. In walking, running, playing football, cycling, skiing, in many other sports and in most forms of work, increased size (within wide limits) is of no particular advantage. In many skilled pursuits, in the most striking and beautiful movements of, for example, gymnastics or dancing, there may well be an inverse relationship between size and the degree of skill attained: the great exponents of these physical skills, such as the Czech and Russian gymnasts, and the great ballet dancers, have never been tall people.

To presume that maximum growth is always best and that the biggest people in the world today, North Americans, should set the reference for the rest of the world's population, appears to me, highly presumptious. As a physiologist interested in the functional capacity of the human body and less interested in static measures such as height, I find it astonishing that functional tests are virtually never used in support of the 'growth potential' theory. In studies in which I was involved some years ago in New Guinea, I remember being not at all surprised that the men we had been measuring, who were muscularly well-developed but small in stature and were subsisting on a diet which appeared only marginally adequate in its nutrient content, had an exercise capacity which was higher than in any well-fed European population (Cotes et al. 1974).

Of course, we can all understand the dilemma of those who have to set standards for growth. It must be absolutely clear that we are not being tolerant of a nutritional state which is so inadequate that children are small and physically weak for their age. There must be not the slightest doubt that small stunted individuals, with subnormal development of muscular and skeletal mass, cannot conceivably be classified as nutritionally 'normal' or acceptable.

However, that does not to me justify setting reference values for height and weight based on American populations. There is no guarantee that the nutriture of such groups is necessarily ideal. We are obsessed with comparing populations, and even individuals, against fixed standards when in reality we do not know enough about the long-term validity, for health and physical efficiency, of such standards, nor do we know much about their relationship to functional physiological tests.

My contention is, therefore, that there is often little to gain by comparing, in any simplistic way, children or adolescents to some arbitrarily-chosen reference values for height, and even less so for weight. Weight is such a highly variable index, because of the virtually unknown importance of large differences in the fat or muscle components, that judging whether or not a child is disadvantaged because he or she is on, for example, the zoth percentile is a highly debatable procedure.

\section{Levels of energy balance in children}

How then are we to assess energy balance in a child or adolescent? It is at least interesting to see what are the levels of the energy intakes. In passing, if by energy balance we are thinking of measurements of both energy intake and expenditure, it 
seems to me not worth attempting to measure $24 \mathrm{~h}$ energy expenditure, other than to obtain some impression of the physical exertion in the different activities of the child's daily existance. Technically it is difficult to do these measurements, and there are few studies to compare with the interesting results recently published by Torun and his colleagues (Torun et al. 1983) on Guatemalan children. However, even if it were possible to make the appropriate measurements by indirect calorimetry of the separate activities of the children, the calculation of total daily energy expenditure in children is open to errors of sufficient magnitude as to make the exercise unprofitable. Indeed, this probably applies to almost any free-living population using currently available techniques. In very careful longitudinal studies on pregnant and lactating women, we have come to the conclusion that an assessment of total daily energy expenditure cannot be done with sufficient exactitude to allow any real assessment of energy balance (Durnin, 1984).

Energy intakes, ideally combined with an estimate of the growing body mass, will tell us a great deal about energy balance in children. Several studies of simple energy intake have been carried out in the UK in recent years on infants, children and adolescents. They are remarkably uniform in certain of their findings, particularly in the apparent almost complete absence of social class differences. These are epitomized by our own recently completed study on $5^{-}$and ro-year-old children living in Glasgow (J. V. G. A. Durnin, M. Martin and F. Forrest, unpublished results).

We measured food intake, by the individual weighed-inventory technique during a period of five consecutive days on each of ninety-three 5-year-old boys, i io 5-year-old girls, 102 10-year-old boys and 125 ro-year-old girls. We also carried out a series of anthropometric measurements on these children (height, weight, skinfold thicknesses, and some skeletal and muscular dimensions).

Table 2 shows the height and weight percentiles, using the World Health Organization (1979) values as the reference, for the four different social groupings into which we have divided these children on the basis of the parents' occupation: I, includes professional and managerial occupations; II, is other types of office workers (the numbers of whom were sometimes smaller than the other groups); III, is skilled manual workers; and IV, includes unskilled workers and unemployed people. There were some differences in height and weight, although only social class IV girls among the 5-year-olds were significantly different. Similar findings were obtained with the ro-year-olds, although social class IV boys were also smaller. However, the energy intakes of the 5-year-old children (Table 3) demonstrate a very different pattern, almost a reversal of the height and weight comparisons. That is, the energy intakes of both boys and girls were significantly higher among social class IV than social class I (and II also for the females) and were the highest values of any of the social groupings. There were no differences in energy intakes between any of the social classes among the ro-year-old children (Table 3).

No differences also occurred in the proportions of energy derived from protein, fat and carbohydrate in the different age and social groups (Table 4 ). 
Table 2. Weight and height percentiles related to social class for 5-6- and Io-I I-year-olds

Social class Wt $(\mathrm{kg}) \quad$ Percentile ${ }^{\bullet}$ oth percentile Height $(\mathrm{m})$ Percentile ${ }^{\bullet}$ oth percentile Males $5-6$ years:

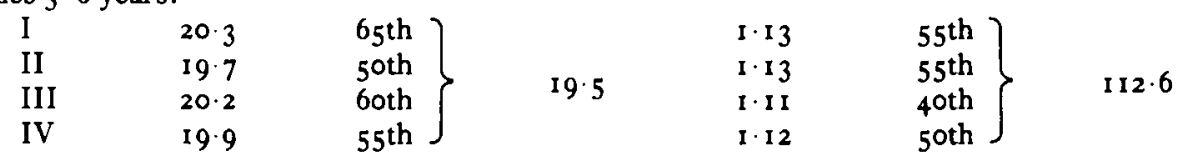

Females 5-6 years:

\begin{tabular}{|c|c|c|c|c|c|}
\hline I & 19.9 & 7oth & & I I I 2 & 6oth \\
\hline II & $20 \cdot 3$ & 75th & 18.4 & I I I 3 & 6oth \\
\hline III & $19 \cdot 1$ & 6oth & 10.4 & $1 \cdot 12$ & 6oth \\
\hline IV & $18 \cdot 1$ & $45^{\text {th }}$ & & I.09 & $35^{\text {th }}$ \\
\hline
\end{tabular}

Males 10-I I years:

$\begin{array}{ll}\text { I } & 34 \cdot 9 \\ \text { II } & 35 \cdot 6 \\ \text { III } & 33 \cdot 1 \\ \text { IV } & 31 \cdot 2\end{array}$

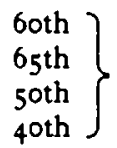

$33 \cdot 0$

$\left.\begin{array}{ll}\text { I. } 4 \text { I } & \text { 6oth } \\ \text { I. } 43 & 7 \text { oth } \\ \text { I. } 39 & 45^{\text {th }} \\ \text { 1. } 37 & 35^{\text {th }}\end{array}\right\}$

Females 10-I I years:

$\begin{array}{ll}\text { I } & 33 \cdot 8 \\ \text { II } & 34 \cdot 8 \\ \text { III } & 33 \cdot 0 \\ \text { IV } & 31 \cdot 0\end{array}$

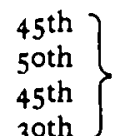

3oth
$34 \cdot 4$

I. 41
I. 4 I
I. 38
I. 35 $\left.\begin{array}{l}5^{\text {oth }} \\ 5^{\text {oth }} \\ 35^{\text {th }} \\ 20 \text { th }\end{array}\right\}$
$139 \cdot 9$

$140 \cdot 9$

-World Health Organization (1979)

Table 3. Energy intakes of different social classes for 5-and 10-year-olds

(Mean values and standard deviations)

Mean daily energy intake

Social class

Males 5 years:

II

Females 5 years:<smiles>[AlH2]</smiles><smiles>[AlH2]</smiles>

III

IV

Males ro years:

$$
\text { I }
$$

II

III

IV

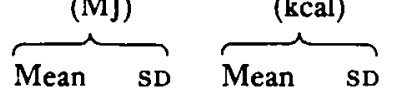

$6 \cdot 54 \quad I \cdot 19 \quad 1564 \quad 284$

$\begin{array}{llll}7.25 & 1.42 & 1733 & 34^{\circ}\end{array}$

$6.76 \quad 1.10 \quad 1616 \quad 263$

$\begin{array}{llll}7.63 & 1.01 & 1775 & 242\end{array}$

$\begin{array}{llll}5.88 & 0.89 & 1406 & 212 \\ 5.90 & 0.88 & 1410 & 211 \\ 6.28 & 1 \cdot 11 & 1500 & 265 \\ 6.41 & 1 \cdot 30 & 1532 & 311\end{array}$

$\begin{array}{llll}8 \cdot 5^{\circ} & 1 \cdot 21 & 2031 & 290\end{array}$

$\begin{array}{llll}8 \cdot 73 & \text { I. } 33 & 2087 & 317\end{array}$

$8 \cdot 54$

I. 56

2042

374

$$
\text { Body-wt (kg) }
$$

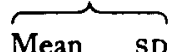

$20 \quad 3$

20

20

20

20

20

19

18

35

36

33

3 I

Females ro years:

I
II
II

$\begin{array}{lllll}7 \cdot 87 & 1 \cdot 29 & 1882 & 309 & 34 \\ 7 \cdot 82 & 1 \cdot 29 & 1868 & 309 & 35 \\ 7 \cdot 86 & 1 \cdot 40 & 1874 & 335 & 33 \\ 7 \cdot 66 & 1 \cdot 76 & 1831 & 421 & 31\end{array}$

Total skinfolds (mm)

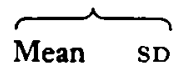


Table 4. Percentage energy derived from protein, fat and carbohydrate for 5- and ro-year-olds

\begin{tabular}{|c|c|c|c|}
\hline Social class & Protein & Fat & Carbohydrate \\
\hline \multicolumn{4}{|l|}{ Males 5 years: } \\
\hline II & 12 & 39 & $\begin{array}{l}50 \\
49\end{array}$ \\
\hline III & I3 & $3^{6}$ & $5 x$ \\
\hline IV & II & 39 & 50 \\
\hline \multicolumn{4}{|l|}{ Females 5 years: } \\
\hline I & I 3 & 39 & 48 \\
\hline II & 12 & 40 & 48 \\
\hline III & I 3 & 39 & $4^{8}$ \\
\hline IV & I3 & 39 & $4^{8}$ \\
\hline \multicolumn{4}{|l|}{ Males Io years: } \\
\hline I & I 3 & $3^{6}$ & $5 \mathrm{I}$ \\
\hline II & I 3 & 39 & $4^{8}$ \\
\hline III & I 2 & 38 & 50 \\
\hline IV & I I & 37 & $5^{2}$ \\
\hline \multicolumn{4}{|c|}{ Females io years: } \\
\hline I & 13 & 40 & 47 \\
\hline II & 12 & $4^{1}$ & 47 \\
\hline III & 12 & 40 & $4^{8}$ \\
\hline IV & 12 & $3^{8}$ & 50 \\
\hline
\end{tabular}

Although the lack of relationship between intakes of energy and nutrients, and growth, have been commented on previously (Widdowson, 1947; Bransby \& Fothergill, 1954; Darke et al. I980a,b; Nelson, 1980), these present results appear to make it very difficult to argue that the lower height and weight percentiles of the social class IV children are much related to nutritional energy intakes. Also, no other nutrient (protein, minerals, vitamins) was present in significantly lower quantities in the diet of the economically poorer children. It is surely possible that genetic factors rather than nutritional may be influencing growth in this population of children from Glasgow.

Table 5 gives further indirect confirmation of the Whitehead et al. (1982) compilation of results on energy intakes of children, which showed an apparently

Table 5. Daily energy intakes and recommended daily allowances $(R D A)$ for 5and 10-year-olds

\begin{tabular}{|c|c|c|c|c|}
\hline \multirow[b]{2}{*}{ Age (years) } & \multicolumn{2}{|c|}{$\begin{array}{c}\text { Mean daily energy } \\
\text { intake }\end{array}$} & \multicolumn{2}{|c|}{ RDA* } \\
\hline & MJ & kcal & MJ & kcal \\
\hline \multicolumn{5}{|l|}{ Males: } \\
\hline 5 & $6 \cdot 9$ & 1655 & $7 \cdot 3$ & $174^{\circ}$ \\
\hline IO & $8 \cdot 4$ & 2033 & $9 \cdot 5$ & 2280 \\
\hline \multicolumn{5}{|l|}{ Fernales: } \\
\hline 5 & 6.0 & 1462 & 7.0 & 1680 \\
\hline IO & $7 \cdot 7$ & I 866 & 8.6 & $205^{\circ}$ \\
\hline
\end{tabular}


steady diminution in these energy values during the past 30 years or more. Table 5 displays considerably lower intakes, mostly of the order of $0.8 \mathrm{MJ} / \mathrm{d}$ (approximately $200 \mathrm{kcal}$ ), than the Department of Health and Social Security (1979) recommendations, with no indication that the intakes were inadequate. These are values for energy intakes, at which balance is occurring, in $5^{-}$and ro-year-old children in Scotland. They might of course not be definitive. However, the number of children studied was large enough to make it likely that the trends were demonstrated with some validity. The relative absence of social class differences similarly shown in our own recent studies on infants (McKillop \& Durnin, 1982), and by other studies on preschool children, surely points to a remarkable social achievement in the UK in recent years.

However, these are gross pieces of information. They need to be accompanied by good information obtained on the same groups by social anthropologists. Most nutritionists are concerned with measuring a particular nutritional state relevant to some specific population group. We sometimes produce interesting and thought-provoking findings. How much more valuable it would be to have these findings integrated into a wider social context, however, so that we could speculate intelligently not only about the fact that energy balance is similar in children from different parts of the socio-economic spectrum, and that energy balance is attained now at lower levels than 20, 30, 40 years ago, but also about some of the underlying reasons and about some of the implications.

\section{REFERENCES}

Beal, V. A. (1980). Nutrition in the Life Span. New York: John Wiley \& Sons.

Bransby, E. R. \& Fothergill, J. E. (1954). British fournal of Nutrition 8, 195-204.

Cotes, J. E., Anderson, H. R. \& Patrick, J. M. (1974). Philosophical Transactions of the Royal Society of London $\mathrm{B268}, 349-36 \mathrm{r}$.

Darke, S. J., Disselduff, M. M. \& Fry, G. P. (1 980a). British fournal of Nutrition 44, 237-252.

Darke, S. J., Disselduff, M. M. \& Fry, G. P. (1980b). British Yournal of Nutrition 44, $243-252$.

Department of Health and Social Security (1979). Recommended Daily Amounts of Food Energy and Nutrients for Groups of People in the UK. Report on Health and Social Subjects no. ${ }_{5}$. London: H.M. Stationery Office.

Dumin, J. V. G. A. (1984). Proceedings of the Asian Nutrition Congress, Bangkok, October 1983 (In the Press).

McKillip, F. M. \& Durnin, J. V. G. A. (1982). Human Nutrition: Applied Nutrition 36A, $4^{0} 5^{-421}$.

Miller, D. S. (1982). Proceedings of the Nutrition Society 4I, 193-202.

Nelson, M. (1980). Proceedings of the Nutrition Society 39, 35-42.

Torun, B., Chew, F. \& Mendoza, R. D. (1983). Nutrition Research 3, 401-406.

Whitehead, R. G., Paul, A. A. \& Cole, T. J. (1982). Human Nutrition: Applied Nutrition 36A, $57-62$.

Widdowson, E. M. (1947). A Study of Individual Children's Diets. Medical Research Council Special Report Series no. 257. London: H.M. Stationery Office.

World Health Organization (1973). Energy and Protein Requirements. Technical Report Series no. 522. Geneva: WHO.

World Health Organization (1979). Measurement of Nutritional Impact. WHO/FAO/79. I. Geneva: WHO. 